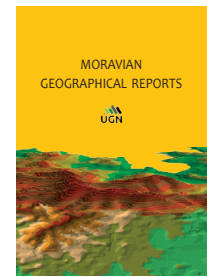

MORAVIAN GEOGRAPHICAL REPORTS

The Czech Academy of Sciences, Institute of Geonics

journal homepage: http://www.geonika.cz/mgr.html

doi: https://doi.org/10.2478/mgr-2020-0008

\title{
Geographies of tacit knowledge transfer: Evidence from the European co-authorship network
}

\author{
Tomáš JECK ${ }^{a *}$, Vladimír BALÁŽ ${ }^{\mathrm{b}}$
}

\begin{abstract}
The patterns of scientific cooperation between the 28 European Union (EU) member countries, Switzerland and Norway, from 1993 and 2017, are evaluated in this article. We consider co-authorship patterns to be proxies for international transfers of tacit knowledge. The theoretical part of the paper contains propositions by researchers in evolutionary economic geography on path-dependence, selection and variation, and the role of networks in knowledge transfer. The principal argument is that the geographical configurations of knowledge transfers over distance are shaped via a set of connectivities - specific communication channels for the exchange of people, goods and knowledge between two or more countries. Some connectivities are more conducive for the transfer of explicit knowledge (e.g. merchandise trade, trade in patents), while human exchange flows (students, migrants, travellers) favour the transfer of tacit knowledge. The research project found that a considerable increase in human exchanges has helped to increase the total number of co-authored papers, but did not amend the geography of the European co-authorship network over last two decades. Rather, the layout of the network stems from a relatively stable set of historical, cultural and political legacies in Europe.
\end{abstract}

Keywords: Cooperation in science, co-authorship patterns, tacit knowledge transfer, evolutionary economic geography, connectivities, Europe.

Article history: Received 8 November 2019, Accepted 30 April 2020, Published 30 June 2020

\section{Introduction}

Contemporary international cooperation in science encompasses virtually all countries of the world. The increase in international collaboration refers not only to technological advancement and the globalisation of trade in goods, capital and knowledge, but also to the increase in science and technology (S\&T) capacity in many countries over the past 30 years (Wagner et al., 2015, p. 7). Common beliefs imply that technological advancement in information technologies and organisational innovations in the transport industry should result in an overhaul of patterns with respect to international scientific collaboration. With the rise of the Internet, the arrival of low-cost airways, and English as a global language, physical Geography and cultural Geography might appear to be less important than ever. Yet, studies on international cooperation in science and technology imply that 'Geography Matters' (Frenken et al., 2009; Morescalchi et al., 2015). As a matter of fact, there is a growing tendency to co-publish with long-distance partners (Frenken et al., 2009). At the same time, co-publication patterns remain geographically localised (Hoekman et al., 2010, p. 667). This conclusion applies also to countries belonging to common economic and political spaces, such as the European Union.

This paper addresses an important gap in research on international cooperation in science. We analyse the distribution of scientific papers co-authored by scientists from at least two European countries. We demonstrate that geographical configurations of knowledge transfers over distance account for a substantial degree of stability over the long term. We argue that the configuration of coauthorship networks is path-dependent and shaped via specific communication channels - 'connectivities'. Some connectivities are more conducive for the transfer of explicit knowledge (merchandise trade, trade in patents, etc.) while human exchange flows (students, migrants, travellers, etc.) clearly favour the transfer of tacit knowledge. Approaches in economic and human Geography are integrated with network science and quantitative analysis. The theoretical part of the paper refers to research propositions by evolutionary economic geographers (EEG) on path-dependence, heredity

\footnotetext{
${ }^{a}$ Institute of Economic Research, Slovak Academy of Sciences, Bratislava, Slovak Republic (*corresponding author: T. Jeck, e-mail: tomas.jeck@savba.sk)

${ }^{\mathrm{b}}$ Institute for Forecasting, Centre of Social and Psychological Sciences, Slovak Academy of Sciences, Bratislava, Slovak Republic
} 
and variation (Essletzbichler and Rigby, 2007; McKinnon et al., 2009), and the role of networks in knowledge transfer (Boschma and Frenken, 2006; Glückler, 2007).

The paper is organised as follows. The second section presents the theoretical background of the study: firstly arguing that scientific work has significant tacit dimensions (Bathelt and Glückler, 2011; Bathelt and Henn, 2014). The transfer of tacit knowledge is tied to face-to-face contact, i.e. human mobility. A survey of relevant literature indicates that human mobility was a neglected variable in studies of international knowledge transfer. The basic propositions of EEG are described and relates these to transfer of tacit knowledge. This section also introduces the concept of 'connectivities' - specific communications channels for the exchange of people, goods and knowledge. Subsequently, data sources and variables used in the analysis are introduced. We conceptualise major drivers shaping configurations of knowledge transfers over distance in Europe from 1993 to 2017. The geographical layout of knowledge transfers is approximated via co-authorship networks. Papers co-authored by partners from at least two European countries in the Web of Science database are used to establish the spatial patterns of intra-European cooperation in science. The evolution of co-authorship networks over time is analysed via network science methods (Easley and Kleinberg, 2010) in the next section. Some major determinants of knowledge transfer are identified and approximated via a set of connectivity variables. Factor analysis and regression are then applied in order to determine the relationships between the network structure and the underlying connectivities. Network organisation in major geographical modules and its evolution over time is the main point of interest subsequently. The path-dependent patterns of centre and periphery are interpreted from the perspectives of EEG. In the conclusions we consider relationships between connectivities and assumptions by EEG on path-dependency and path-creating in the European co-authorship networks.

This application of a connectivity approach is a novelty in research into co-authorship networks. We identify major connectivities in trade in knowledge and goods, as well as in human mobility, in shaping the geography of European coauthorship networks. We use such connectivities to explain the evolution of the geography of scientific cooperation over a quarter of a century. Indicators of human exchange are, to our best knowledge, used for the first time to study the geographical layout of international cooperation in science. Other original aspects of this work include the focus on intra-European cooperation, the long-term view ( 25 years), and the high number of publications analysed.

\section{Theoretical background}

\subsection{The tacit dimension of scientific work}

The concept of tacit knowledge was introduced by Polanyi (1966, p. 4): "We know more than we can tell." Tacit knowledge refers to knowledge that we know that we possess but are unable to quantify - or even express, according to some authors. Tacit knowledge can be only 'produced in practice' (Maskell and Malmberg, 1999, p. 172) and acquired only via personal experience, such as the "informal take up of learned behaviour and procedures" (Howells, 2000, p. 53). As summarised by Nonaka and Krough (2009, p. 606): "Knowledge that is uttered, formulated in sentences, and captured in drawings and writing is explicit. Knowledge tied to the senses, tactile experiences, movement skills, intuition, unarticulated mental models, or implicit rules of thumb is tacit." Typical examples of tacit knowledge include knowing "how to ride a bicycle", "how to do a surgery" and/or "how to write a scientific paper". The key difference between explicit and tacit knowledge relates to the mode of acquisition and transferability. While it is easy to send the results of an experiment via post or email, the ability to perform an experiment is subject to personal learning.

Blackler (2002) recognises four types of tacit knowledge:

1. Embrained knowledge helps individuals to recognise underlying patterns and organise information according to specific narratives. Establishing scientific theories from a large body of measurements is an example of embrained knowledge in scientific work;

2. Embedded knowledge helps us to understand routines, roles and procedures without conscious learning. How to conduct an experiment, how to fine-tune research procedures and how to write a scientific paper are examples of embedded knowledge. Many research procedures contain a tacit component, which is difficult to learn and transfer without face-to-face contact;

3. Embodied knowledge refers to intuitive manual and cognitive skills stored in the 'body and mind' (Toner and Wooley, 2008). The acquisition of embodied knowledge helps to operate along intuitive pathways and undertake working tasks effortlessly; and

4. Encultured knowledge refers to collective tacit knowledge shared by individuals. It derives from shared understandings via socialisation and acculturation. Science is international, but scientific work happens within specific cultural environments. Encultured knowledge relates not only to cultures of nations and ethnic/social groups, but also to various organisational cultures. Socialisation and acculturation build both affect-based and cognition-based trust. Such trust, in turn, promotes the use and transfer of tacit knowledge (Holste and Fields, 2009).

Communication in joint research projects can take many forms. Modern technologies (e-mail, Skype, Zoom, etc.) enable the exchange of ideas without a physical presence. Yet, some research tasks are difficult to perform over distance. Each creative task has a tacit dimension. The tacit dimension is difficult to transfer without face-to-face contact. Tacit knowledge is a necessary (if not sufficient) precondition for trans-local cooperation. While all four types of tacit knowledge are necessary preconditions for scientific work, encultured knowledge is a key determinant for the geography of international cooperation in science. Geographical space forms 'cultural, social and psychological space through which knowledge is generated and imparted' (Howells, 2002, p. 874). Research institutes and countries may differ vastly in their languages, social norms, cultural habits, historical and socio-cultural heritages and/or organisational routines. The lower the barriers (and the stronger the enhancers), the easier the cooperation. Knowledge transfer is enhanced when partners already share relational proximity based on former joint work experiences or close social relations (Bathelt and Glückler, 2011). As for the cooperation with respect to patents and publications, face-to-face contact is the only way in which to acquire and transfer tacit knowledge. Most co-authors of scientific papers tend to know each other in person. Many of them work on joint international projects and engage in frequent 
personal exchange in conferences, seminars and/or longterm visits. Face-to-face meetings help to build trustbased linkages (Bathelt and Henn, 2014) and enhance the potential for future co-publications.

\subsection{Evolutionary economic geography and networks of co- operation in science}

The EEG is inspired by evolutionary economics. It considers the spatial distribution of economic activities as an outcome of largely connected and path-dependent historical processes (Koegler, 2015). Path-dependency is a key concept of EEG. Path-dependency results from cumulative causation. Events occurring in the past may have long-term effects on current and future operations of the networks of firms, institutions or individuals. Other important concepts in EEG include variety, selection and retention (Essletzbichler and Rigby, 2007). The retention process refers to cumulative reproduction and reinforcement of the network structure. Variation, on the other hand, refers to mechanisms of novelty, disruption and potential path disruption. The EEG primarily analyses evolution of formal institutions (such as firms, countries, governance bodies) and informal institutions (such as clusters and networks). The EEG considers institutions as relatively stable entities that change only slowly over time, but this can be disrupted by sudden events as new development pathways are opened and new pathdependent trajectories established. The focus on historical perspectives and evolution makes EEG different from the new economic geography (NEG) and institutional economic geography (IEG). The NEG considers agglomeration effects and concentrates on transport and transaction costs, while IEG explains differences in spatial development via different sets of institutions.

Actors usually operate within networks, and the process of selection is driven by the activities of agents. Networks are vehicles for transactions in goods, services and knowledge. Connections in a network are relations between pairs of agents. The selection of a partner is determined not only by external pressures, but also by the decisions of actors. Actors operate under uncertainty and bounded rationality, and the formation of ties is subject to considerations of potential costs and benefits. It is better to engage in transactions with minimal costs, and to transact with agents with similar geographic, cultural, institutional and cognitive settings. Actors generally would explore ties with partners with whom they are most familiar. As noted by Essletzbichler and Rigby (2007, p. 557) actors would use 'relational assets based on the social properties of (localised) networks including tacit knowledge, embedded routines, habits and norms, local conventions of communication and interaction, reciprocity and trust'. For successful cooperation it is important to be in the right network, but also in the right place within a network. The structure of a network is established via the social interaction of actors (network 'nodes'), and incumbent actors would prefer cooperation with their current partners. Any new entrants would seek attachments to well-connected partners ('influential nodes') so as to benefit from multiple connectivities. Influential nodes further increase their connectivity, while peripheral nodes tend to remain peripheral, a process is known as 'preferential attachment' (Glückler, 2007). The preferences of incumbent actors for their current partners, as well as new entrants for influential nodes, results in cumulative causal patterns and reinforces the centre-periphery structure of the network.
The architecture of networks, with regard to flows of goods, knowledge and people, tends to follow rules of geographical, cultural and linguistic proximity (Luukkonen et al., 1992; De Prato and Nepelski, 2004; Felbermayr and Toubal, 2010). Boschma (2005) recognises four types of proximity. Cognitive proximity (the proximity of embrained knowledge) is the degree of overlap in two agents' knowledge bases. The overlap is an indispensable condition for efficient communication. Organisational proximity is the extent to which relations are shared in an organisational arrangement, either within or between organisations. Social proximity refers to social embeddedness of agents in terms of friendship, kinship, and experience. Common organisational and social routines, roles and procedures (embedded tacit knowledge) promote better cooperation. Effectively, such embeddedness is a precondition for forming trust. Geographic proximity is represented as the physical distance between agents.

Jennissen (2007) introduced the concept of 'connectivities', as a factor that embodies specific communication channels for the exchange of people, goods and knowledge between two or more countries. Connectivities support building relational assets and reducing transaction costs. Furthermore, Jennissen (2007, p. 420) recognises two types of connectivity:

1. Cultural connectivity involves multidimensional shared institutional legacies such as language, political and cultural history and/or legal systems. Cultural connectivity is a proxy for cognitive and organisational proximity. Possessing knowledge of a partner's language, culture and/or organisational setups (embrained, embedded and encultured knowledge) has two advantages: it makes mutual communication easier and the results of exchange more predictable; and

2. Material connectivity includes technologically influenced geographical proximity such as transport and communication networks conducive to international exchange in trade, goods and knowledge. Moreover, it decreases transport and other transaction costs. Shares of neighbouring countries in total merchandise trade often are higher than expected with respect to the size of their economies.

Material and cultural connectivities sometimes overlap, as many neighbouring countries share their languages and cultures. Connectivities help to reduce uncertainty regarding transaction outcomes and, thus, transaction costs between partners from different countries (Howells, 2002; Bathelt and Henn, 2014). Shared institutional legacies explain why much of the intra-European exchange of goods, people and knowledge is path-dependent and facilitated by long-term connectivities.

\subsection{The research gap}

Do configurations of knowledge transfer over distance exhibit some distinctive geographical patterns? The substantive literature on international cooperation in science does indeed indicate that co-authorship patterns follow some well-established economic, cultural and political configurations.

Two principal methods are applied in the study of international collaboration in science: network analysis and gravity models (see Tab. 1). Network analysis examines certain properties of collaborative networks, such as network density and measures of centrality. Network science has 
been applied to the study of the structure and evolution of scientific landscapes and early studies mapped co-authorship networks in specific scientific fields such as biomedicine and physics (Newman, 2004). Other streams of research have concentrated on the economic, cultural and political geography of international collaboration in science. Studies in this stream usually find considerable heterogeneity of the European research space (Wagner et al., 2017). Moreover, gravity models are often applied in spatial analysis, as these models observe predicted and actual flows of goods, services, patents and/or migrants and analyse differences between predicted and observed exchanges. It is noted that exchanges between country pairs are proportional to some hurdles (such as distance) or to some enhancers (such as trade agreements or common languages).

The unit of analysis varies in studies of international collaboration in science, determining both the sample size and the availability of explanatory variables (see Tab. 1). Some papers on co-publications use data on authors' home institutions (Pan et al., 2012), whereas city-level analysis enables the construction of very large networks. Most studies on European cooperation in science focus on NUTS 2 or NUTS 3 regions (plus Norway and Switzerland). Physical distance and regional dummy variables (neighbourhood, institutional and cultural effects, technological distance) and research and development (R\&D) capacities (R\&D spending, R\&D personnel) are usually employed as explanatory variables in network analysis and gravity models. The regional approach allows for a sample size between 175 (Paci and Usai, 2009) and 5,552 members (Chessa et al., 2013). The common finding is that neighbouring countries and regions cooperate more often than distant ones. Regional dummy variables are proxies for cultural and linguistic barriers in network analysis and gravity models. Large samples are best suited for network analysis, but are accompanied by a drawback - the limited numbers of potential explanatory variables. The acquisition and transfer of tacit knowledge is possible only via human exchange, and regional dummies cannot directly measure the potential for the transfer of tacit knowledge. Data for some potentially important explanatory variables (flows of migrants, travellers or students) are available only at the country level. We assume that data on human exchanges are the best possible proxies for the transfer of tacit knowledge.

This survey of the relevant literature indicates two research gaps. Firstly, all papers are empirical in their nature. They follow the evolution of cooperation in science and technology, but provide no conceptualisation of such evolution. Interestingly, most papers in the survey refer to the influential papers by Boschma (2005) and Boschma and Frenken (2006), but none of them interprets their findings in terms of EEG. Several important events happened in the period 1993-2017: four rounds of the EU enlargement; the introduction of the Schengen area; the 2008 financial crisis; and the creation of the European Research Area. This long period provides an unique opportunity to test the EEG assumption on path-dependency and path-creation. Secondly, no paper focuses on the role of tacit knowledge in international cooperation in science. If tacit knowledge can be acquired and transferred only via face-to-face contact, proxies for human exchange are needed in order to understand the impact of tacit knowledge on the geography of international cooperation in science.

Referring to the assumptions of EEG, we propose the following hypotheses:
- H 1: Connectivities in trade in goods and knowledge, as well as in human mobility, explain a substantial part of the configuration of co-authorship networks;

- H2: The importance of human exchange for the geography of European co-authorship networks increases over time; and

- H3: Connectivities in trade in knowledge and goods, as well as in human mobility, are shaped by shared longterm historical, cultural and political legacies. The pathdependent architecture of co-authorship network implies its relative stability and resilience to disruption.

\section{Data and methods}

\subsection{Area of study}

This paper focuses on intra-European cooperation in science for two main reasons. The first reason relates to a shared general institutional framework. Continuing integration of the European Economic Area (EEA) is well visible in the movement of goods, capital and people. All EEA citizens enjoy freedom of travel and the majority pay with a common currency. High levels of social and economic development and well-operating transport networks promote researcher and student mobility within the EEA. The second reason relates to a set of science-specific policies, regulations and instruments. The development of intra-European collaboration in science is promoted via specific EEA-wide legislation and support measures, such as Framework/ Horizon Programmes, large research infrastructure, and transnational research networks (Nedeva, 2012).

\subsection{Time period}

The evolution of the European scientific landscape has been shaped by a high number of socio-economic events and policies. Some events have shaped the evolution of general socio-economic and political spaces in Europe. The most important events probably include:

i. The 1995, 2004, 2007 and 2013 enlargements;

ii. The introduction of free movement within the Schengen area in 1995; and

iii. The onset of the 2008 financial and economic crisis; and the most important science-support policies including

iv. Creation of the European Higher Education Area (the Bologna Process) in 1999;

v. The establishment of the European Research Council (ERC) in 2007;

vi. The launch of the Joint Programming process in 2008;

vii. The assistance to international collaborative research under the Framework Programmes; and

viii. Support from the Structural and Cohesion Funds to research, technology and innovation.

Studying the evolution of co-authorship networks over a quarter of a century implies sub-dividing the long time period into two or more shorter ones. The choice is not easy, as none of the above-mentioned events worked in isolation. The impacts of these events on the European scientific landscape tend to be multiplicative and synergetic over time.

The 1995 enlargement included three small countries (Austria, Finland and Sweden). Furthermore, it is too early to evaluate its impacts in the 1993-2017 time series. The 2004, 2007 and 2013 enlargements involved 13 countries from the east and south of Europe. These countries had 


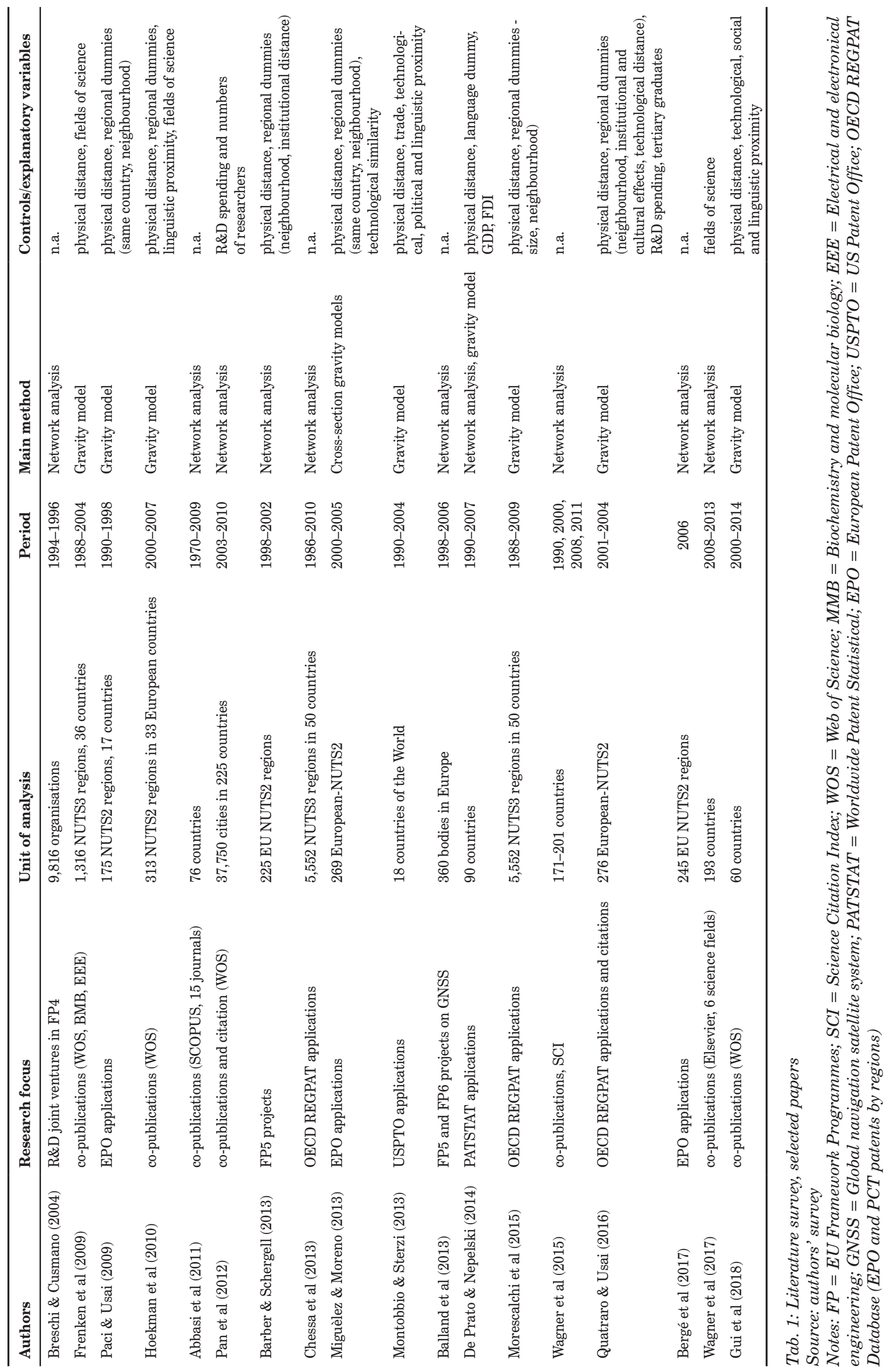


limited scientific capacities. The benefits of the Schengen and Bologna Processes are spread out over time, and it is difficult to tie them to specific years. The 2008 economic crisis might have had an effect on some national exchange and scholarship schemes, but these were probably less important than the EU schemes, which were largely not impacted by the crisis.

The most important policies aimed at fostering international (and, specifically, intra-European) cooperation in science and technology were implemented after 2007. There was a substantial increase in funding between the Sixth Framework Programme (2002-2006; €16.3bn) and the Seventh Framework Programme (2007-2013; €53.2bn, European Commission 1994-2013). The Framework Programmes were explicitly designed to support the creation of the European Research Area (ERA).

We therefore decided to analyse the development of European scientific collaboration in two distinctive periods: 1993-2006 and 2007-2017. The collaboration patterns studied pertain to the EU28 countries, plus Switzerland and Norway (hereinafter referred to as 'European countries').

The data were extracted from the Web of Science Core Collection database (hereinafter referred to as 'WOS') ${ }^{1}$. The database contains 47.67 million entries, of which 15.65 million papers were single-authored/co-authored by at least one European scientist. The latest figure includes 4.77 million papers co-authored by at least two partners from the European countries in the period 1993-2017².

\subsection{Variables}

Country pairs are the unit of analysis for the co-authorship patterns. The dependent variable is expressed as

$$
\frac{c p_{i j}}{\sum_{j}^{29} E c p_{i}}
$$

where $i \neq j ; i=1 . . .30 ; j=1 . . .29$.

The numerator concerns the number of co-publications of country $i$ with country $j$ and the denominator relates to the total number of co-publications of country i with all European countries ('European co-publications'). The explanatory variables are expressed in a similar way. The variable for the merchandise exports, for example, is expressed as

$$
\frac{m e_{i j}}{\sum_{j}^{29} E m e_{i}}
$$

where $i \neq j ; i=1 . . .30 ; i=1 . .29$.

The choice of explanatory variables is based on different types of connectivity. The sample structure implied a preference for a relatively low number of explanatory variables. We did analyse, however, a high number of connectivity-type variables. The eight independent variables showing the highest correlations with the dependent variable were selected. ${ }^{3}$
Firstly, we include three indicators of international trade in knowledge: patents with foreign co-inventors, as a measure of mutual research cooperation (variable 1); foreign ownership of domestic inventions (variable ); and domestic ownership of foreign inventions (variable 3). All variables are measured via shares of the $j$-th European patenting partner in total joint European patents by the $i$-th European country. Cooperation on patents frequently is accompanied by published joint scientific papers. Data on trade in patents were extracted from the OECD Patent Database (OECD, 2019);

Secondly, international merchandise trade is measured via shares of the $j$-th European trading partner in total European merchandise imports and exports by the $i$-th European country (variables 4 and 5). We assume that international trade is strongly related to international community gatherings, international business travel, and transnational network relations. Some current trade flows refer to previous cooperation in science and technology. Data on merchandise trade were extracted from the UNCTAD database (UNCTAD, 2019); and

Thirdly, human mobility was approximated via three variables. The share of the $j$-th European destination in total emigrants from the $i$-th European country of origin (variable 6) is a proxy for long-term human mobility. The share of the $i$-th European student destination in total tertiary students originating from the i-th European country (variable 7) approximates human exchange in higher education and research. The share of nights spent by tourists from the $i$-th European country in nights spent by all European tourists in the $i$-th European country (variable 8) approximates short-term human mobility, including mobility by businessmen and researchers. Variables 6,7 and 8 are proxies for face-to-face contact, building foreign experience and trust and transferring tacit knowledge. Data on migration exchange and tourist exchange were extracted from the Eurostat database. The OECD database on foreign and international students and the Eurostat database were sources of data on international students.

Data for the dependent variable have been available for 30 European countries from 1993 to 2017. Data for independent variables have been available from 1993 to 1998, depending on the variable type. Descriptive statistics for the dependent and independent variables are presented as an Appendix 1 (see below).

\subsection{Analytical methods}

The unit of analysis and the availability of data have impacts upon the choice of analytical methods. Traditional gravity models suffer from some pitfalls, in that they allow for no missing data and/or zero exchanges. Regression methods assume the independence of explanatory variables. These assumptions are often difficult to meet. In World trade models, for example, one third to one half of countries do not trade with one another or trade only in one direction (Helpman et al., 2008, p. 447). A substantial part of the bilateral trade matrices is missing (Haveman

\footnotetext{
${ }^{1}$ Papers by German authors, for example, were most frequently co-authored by partners from the UK (16.9\%) and France (11.5\%) in the period 1993-2017

2 The download option does not enable recording the numbers of cooperating authors. A paper co-authored by three Dutch authors and one French author, for example, is reported as one Dutch-French cooperation

${ }^{3}$ Note: We examined alternative variables, such as road distance. These variables produced low communalities (below 0.2 ) and were therefore excluded from further analysis
} 
and Hummels, 2004, p. 211). The problem of missing or zero values applies also to explanatory variables. Moreover, the gravity model results may be difficult to interpret, due to questions regarding data completeness and other influencing factors (Ramos, 2016).

All explanatory variables in our model were strongly correlated. Most Pearson correlation coefficients were higher than 0.7 (see the Appendix 2 below). Hence, multicollinearity problems arise.

We considered strong assumptions with respect to missing data, zero flows, and multicollinearity. We opted for an approach alternative to the gravity model: we applied factor analysis in order to reduce the number of explanatory variables and mitigate the multicollinearity risk. This approach enables integrating multiple explanatory variables into meaningful factors ("connectivities"), which are easier to interpret from the perspectives of economic geography.

\section{Connectivities: Determinants of the network's configuration}

Factor analysis is often used to reduce the large number of variables to a smaller number of factors. Factor scores are then used as inputs to a regression analysis so as to overcome the issue of multicollinearity, as they can be estimated as (truly) independent variables.

\subsection{Factor analysis}

Application of factor analysis is subject to some considerations, such as the sample size, numbers of factors and variables, and methods of factor extraction/ rotation. Any quantitative analysis of European co-authorship patterns must consider the sample of the European country pairs $(\mathrm{N}=620-870$, see Appendix 1 below). Conducting factor analysis requires meeting some specific criteria (de Winter et al., 2009). The sample size is a function of communalities, factor loadings, factor numbers and variable numbers. Communalities should be higher than 0.6 , while the number of factors and variables should be low. Indicators of sampling adequacy must be above certain thresholds: the Kaiser-Meyer-Olkin (KMO) measure of sampling adequacy should exceed 0.7. We checked the above-mentioned recommendations on communalities, KMO statistics, and factor and variable numbers. All communalities obtained in the analysis were above 0.7 . The KMO statistics were close to 0.9 (Tab. 2) in both periods.

The connectivities in merchandise trade, knowledge trade and human exchange are mutually correlated. Oblique rotation should be preferred to orthogonal rotation in confirmatory factor analysis (CFA) in the case of interrelated factors (Osborne, 2015, p. 5). In most cases, oblique rotation provides a more realistic representation of how factors are interrelated (Brown, 2014, p. 28; Costello and Osborne, 2005, p. 5).

The pattern matrix is examined for factor loadings using oblique rotation methods. Three factors were detected (see Tab. 2):

- Factor 1 - Trade in knowledge (variables 1 to 3);

- Factor 2 - Trade in goods (variables 4 and 5);

- Factor 3 - Human exchange (variables 6 to 8).

All three factors had high pattern matrix loadings on expected variables. Three factors explained $83.054 \%$ of the total common variance in the period 1993-2006 and 83.047\% in the period 2007-2017.

\subsection{Regression analysis}

Anderson-Rubin factor scores were produced in the factor analysis. The method allows factor scores to be uncorrelated (DiStefano et al., 2009, p. 5). We checked for the correlation of all three factor scores: all correlation coefficients were lower than 0.265. Anderson-Rubin factor scores for Factors 1, 2 and 3 were used as independent variables in the OLS regression model (Tab. 3). The adjusted R-squared was 0.757 for the period 1993-2006 and 0.719 for the period 2007-2017. All variables had expected (positive) signs: i.e. the higher the partner share in trade in patents and goods and human exchange, the higher the partner share in European co- publications.

The strength of the effect of each independent variable on the dependent variable can be measured via the standardised beta coefficient (Beta). Factor 1 - Trade in knowledge (variables 1 to 3 ) accounted for the highest Beta coefficients and significance levels in both periods. Factor 2 - Trade in goods (variables 4 and 5) accounted for the second-highest, and Factor 3 - Human exchange (variables 6 to 8) for the third-highest Beta coefficients and significance levels in both periods.

\begin{tabular}{|c|c|c|c|c|c|c|}
\hline & \multicolumn{3}{|c|}{$1993-2006$} & \multicolumn{3}{|c|}{ 2007-2017 } \\
\hline & F1 & F2 & F3 & F1 & F2 & F3 \\
\hline Percent of variance explained & 67.81 & 10.90 & 4.35 & 65.15 & 8.44 & 9.46 \\
\hline Domestic ownership of inventions made abroad & 0.811 & -0.051 & 0.162 & 0.974 & -0.078 & -0.057 \\
\hline Patents with foreign co-inventor(s) & 0.895 & 0.132 & -0.003 & 0.860 & 0.100 & 0.080 \\
\hline Foreign ownership of domestic inventions & 0.377 & 0.478 & 0.024 & 0.509 & 0.286 & 0.102 \\
\hline Merchandise exports & -0.009 & 0.873 & 0.114 & 0.040 & 0.837 & 0.074 \\
\hline Merchandise imports & 0.049 & 0.852 & 0.070 & -0.008 & 1.024 & -0.039 \\
\hline Migration exchange & 0.026 & 0.042 & 0.860 & -0.040 & 0.029 & 0.910 \\
\hline Student exchange & 0.130 & 0.095 & 0.708 & 0.007 & -0.071 & 0.945 \\
\hline Nights spent & 0.066 & 0.112 & 0.695 & 0.114 & 0.208 & 0.596 \\
\hline
\end{tabular}

Tab. 2: Confirmatory Factor Analysis, pattern matrix (Notes: Kaiser-Meyer-Olkin Measure of Sampling Adequacy: 0.898 for 1993-2006 and 0.856 for 2007-2017. The oblique rotation produces pattern matrix. In the pattern matrix, loadings on specific factors are regression coefficients. Pattern loadings can fall beyond range [-1, 1])

Source: authors' computations 


\begin{tabular}{|c|c|c|c|c|c|c|c|c|c|c|}
\hline & \multicolumn{5}{|c|}{ 1993-2006 } & \multicolumn{5}{|c|}{ 2007-2017 } \\
\hline & B & Std. Err & Beta & $\mathrm{t}$ & sig & B & Std. Err & Beta & $\mathrm{T}$ & sig \\
\hline constant & 4.824 & 0.176 & & 27.335 & 0.000 & 4.141 & 0.117 & & 35.490 & 0.000 \\
\hline Factor 1 & 4.548 & 0.204 & 0.695 & 22.244 & 0.000 & 2.543 & 0.109 & 0.612 & 23.225 & 0.000 \\
\hline Factor 2 & 1.685 & 0.137 & 0.372 & 12.320 & 0.000 & 1.367 & 0.090 & 0.396 & 15.125 & 0.000 \\
\hline \multirow[t]{2}{*}{ Factor 3} & 1.070 & 0.139 & 0.241 & 7.697 & 0.000 & 1.130 & 0.092 & 0.323 & 12.312 & 0.000 \\
\hline & \multicolumn{5}{|c|}{$\mathrm{R} 2=0.872 ;$ Adjusted $\mathrm{R} 2=0.757$} & \multicolumn{5}{|c|}{$\mathrm{R} 2=0.849 ;$ Adjusted $\mathrm{R} 2=0.719$} \\
\hline
\end{tabular}

Tab. 3: Linear regression with the factor scores

Source: authors' computations

The findings of the regression analysis confirm Hypothesis 1: long-term connectivities in trade in goods and knowledge, as well as human mobility, explain a substantial proportion of the European patterns of co-authorship. The Beta value for the trade in knowledge (Factor 1) somewhat decreased between the two periods, but remained the strongest predictor of co-authorship patterns. The Beta values for merchandise trade and human mobility increased over the two periods. Interestingly, human mobility (Factor 3) accounted for the highest increase in Beta value (Hypothesis 2). The increase in Beta for Factor 3 may reflect the EU's 2004, 2007 and 2013 enlargements. Such an increase in Beta value corresponds to an increase in intra-European human exchange. The absolute volume of intra-European migrants, for example, increased 2.69 times, while the nominal value of exports increased only 1.35 times between 2006 and 2017.

\section{Geographical patterns of European co-authorship}

To date we have identified some factors (connectivities) that are important for configurations of knowledge transfers over distance. Some factors increased while some decreased in importance for the overall configuration of co-authorship networks. Have these changes resulted in any significant reconfiguration of the co-authorship network?

We examine the patterns of scientific cooperation between the 28 EU member countries, Switzerland and Norway. The analysis starts in 1993 , wherein all of the above-mentioned countries already existed and papers co-authored by their nationals were reported in the WOS database $^{4}$. We therefore analyse the development of the same network over 25 years.

\subsection{Co-authorship modules}

The spatial configuration of European scientific cooperation (and its changes over time), is examined first of all via standard network measures such as the average weighted degree (Easley and Kleinberg, 2010). There was a substantial increase in the intensity of cooperation. The average weighted degree increased from 5,806.13 from 1993-2006 to 22,771.67 from 2007-2017. Shares of co-publications by scientists from at least two European countries, Norway and Switzerland, in relation to total scientific output, increased from $27.1 \%$ in the period $1993-2006$ to $34.9 \%$ in the period 2007-2017. Small countries with open economies, well-diversified research systems and a high intensity of public support with respect to research, were the main beneficiaries of international cooperation. Co-authorship shares, for example, increased much more for Belgium, Denmark and Finland than for Greece, Portugal and/or Slovakia. The considerable increase in intensity of cooperation, however, did not result in any substantial changes in the network structure. The basic topology of the European co-authorship network remained remarkably stable. This finding supports Hypothesis 3 and also assumptions by the EEG on cumulative reproduction of the network structure.

The network diagrams (Fig. 1) visualise patterns of European scientific cooperation in the periods 1993-2006 and 2007-2017. The circles in the diagram (nodes) represent European countries. The connecting lines (edges) between nodes describe the number of connections and the intensity of cooperation (in terms of co-authored papers). Edge thickness corresponds to the average annual number of co-authored papers in the specific time period. The thick line between the United Kingdom (UK) and Germany (DE), for example, represents 4,096 papers co-authored by German and British scientists annually in the period 1993-2006, which is, by far, the largest cooperation link (Fig. 1). Node sizes reflect the intensity of cooperation between specific countries. The degree of a node (country) is a simple number of connections with other nodes (countries). The degrees of nodes are weighted by the edge thickness (intensity of cooperation). The UK and Germany accounted for the highest numbers of co-authored papers, and the respective nodes for these countries are the largest circles in the network diagram. We used the Fruchterman-Reingold (FR) layout algorithm to visualise the nodes and edges in a web (Fig. 1$)^{5}$.

Complex graphs tend to be divided into distinctive modules (communities). Modules are "densely connected groups of nodes with only sparser connections between groups" (Newman, 2006, p. 6). Seven communities were detected in the periods 1993-2006 and 2007-2017:

1. North West (United Kingdom, Netherlands, Belgium, Luxembourg and Ireland);

2. Central Europe (Germany, Austria, Switzerland, and some new member countries, notably the Czech Republic, Hungary, Poland and Croatia);

3. Scandinavia (Denmark, Norway, Sweden and Finland, and Estonia, Latvia and Lithuania);

4. Iberia (Spain and Portugal);

5. Italy and France;

\footnotetext{
${ }^{4}$ The Czech and Slovak Republics were established as independent nations on $1^{\text {st }}$ January 1993

5 The FR algorithm belongs to a family of force-directed layout algorithms. Nodes are repositioned until they stabilise when the energy of the system is minimised and the system reaches an equilibrium state (Fruchterman and Reingold, 1991)
} 
6. South East / Balkans (Greece, Cyprus, Romania and Bulgaria); and

\section{Slovakia and Slovenia.}

Specific communities seem to mirror patterns of geographical, cultural and linguistic proximities. The proximities lowered barriers to the transfer of encultured tacit knowledge, and enhanced cooperation between research partners. The communities also correspond to the traditional, albeit changing, spheres of influence of the major European powers in terms of policy, trade and culture (Moravcsik, 1991).

Communities (1)-(4) remained stable in the two periods compared. Loosening ties between Italy and France and the emergence of separate communities for these countries, were major changes in the community structure between the periods 1993-2006 and 2007-2017. France developed more ties with Romania, Poland and Luxembourg. The Czech Republic and Slovakia formed a new community: this community no doubt operated on shared historical legacies, and physical, organisational and social proximity. Croatia,
Slovenia and, rather surprisingly, Latvia, Lithuania and Estonia had cooperated more with the South East/Balkan community. The whole South/East community appears to be connected to Italy. It should, however, be noted that all members of the South and East communities (except for Italy), as well as Slovakia and Slovenia, account for low publication intensity compared to advanced EU member countries. A relatively small increase in publication intensity and diversification of international collaboration is reflected in the regrouping of community members. Hoekman et al. (2010) found that researchers from the European periphery were more likely to collaborate with international partners than were researchers in countries of the European core. This is understandable, as researchers in peripheral countries are less likely to benefit from high-quality research infrastructure. Furthermore, they have more limited choices of partners in their own countries and fields of research. The finding supports assumptions by the EEG on preferential attachment: new entrants to co-authorship networks preferred to connect to well-connected influential partners in Europe's core.

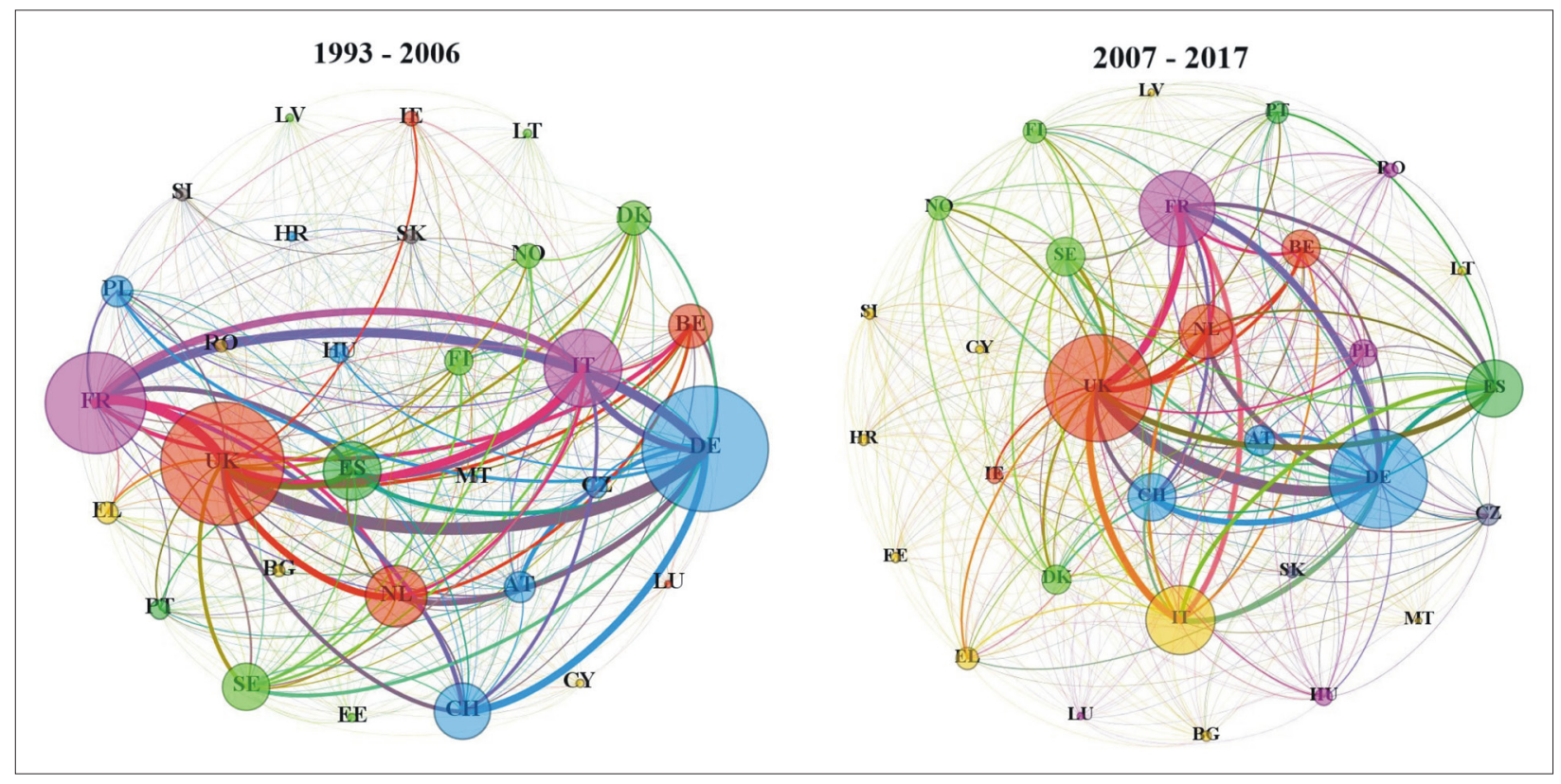

Fig. 1: The network diagram for patterns of European scientific cooperation in the periods 1993-2006 and 2007-2017 Source: authors' elaboration

\subsection{Rich club and core-periphery}

Complex networks may have very different architecture. In some networks, relatively few influential nodes are strongly interconnected, and the 'rich' nodes are much more likely to form tight and well-interconnected cliques (clubs) than are low-degree nodes (Colliza et al., 2006, p. 110). In a weighted network, the 'rich club' is a phenomenon wherein some prominent nodes direct their strongest ties towards one another to a greater extent than randomly expected (Opsahl et al., 2008). Traffic between members of the 'rich club' accounts for a substantial proportion of total traffic in the network. The influential nodes also collect high numbers of connections with peripheral nodes.

Traffic between peripheral nodes, on the other hand, is quite weak. 'Rich club' architecture is typical for air traffic systems with major hubs, Internet networks and/or tourist exchange. Examples of the rich club in weighted networks include the global trade network (Zlatic et al., 2009), airline networks (Barrat et al., 2004; Opsahl et al., 2008) or mobility patterns with respect to the Chinese population during national holidays (Wei et al., 2018).

As for scientific publications, the European 'rich club' consists of the UK, Germany, France, Italy, the Netherlands, Spain and Switzerland. The above-mentioned seven countries generated $95.4 \%$ of European papers (singleauthored and co-authored) in 1993 . The respective share of the rich club had decreased to $86.5 \%$ by 2017 , but the decrease was slightly accelerated after the 2004 eastern enlargement of the EU. Some EU members deriving from the 2004, 2007 and 2013 enlargements increased their publication intensity by as much as ten-fold in the abovementioned period. Moreover, they were more likely to coauthor their papers with other members of the periphery, outside of the 'rich club'. Shares of single-authored and co-authored papers by new EU member countries out of the total number of European papers increased from 6.1\% 
to $14.2 \%$ in the period $1993-2017^{6}$. The basic structure of the co-authorship network, however, remained dominated by the rich club of seven countries. The persistence of the 'rich club' confirms Hypothesis 3 regarding the relative stability of the geographical patterns of co-authorship. It also supports assumptions by the EEG on the cumulative causation and reproduction of the network structure.

The core-periphery structure of international collaboration patterns is by no means restricted to Europe. De Prato and Nepelski (2014) used data from the European Patent Office (EPO) and the Worldwide Patent Statistical Database (PATSTAT) to map the global technological collaboration network. They found the network to be dominated by major global powers: USA, UK, China, France and Japan. These few hubs were complemented by a high number of peripheral countries. The structure of the collaboration was determined by linguistic proximity and spatial proximity. The hierarchical structure of international scientific collaboration patterns is well visible also at regional levels: Bergé et al. (2017) examined the European co-patent network in order to analyse cooperation in R\&D at the NUTS 2 level, finding that a relatively small number of German, French, Swiss and Belgian regions played key roles in international copatents. The centre-periphery and 'rich club' patterns were also detected at similar regional levels in Europe (Breschi and Cumano, 2004).

\section{Discussion, conclusions and directions for further research}

This paper contributes to the literature on international cooperation in science and technology. It uses propositions of the EEG to explain the evolution of the European coauthorship network over a turbulent period of political and economic changes in Europe in the period 1993 to 2017. The paper combines the theoretical assumptions by the EEG with extensive quantitative analysis to identify major factors of the network architecture and changes in the network structure over time.

The EU's common economic, cultural and political spaces ('connectivities') were extremely important for building European co-authorship networks. Promotion of the four freedoms of the single market, joint research programmes, as well as innovations in international travel, vastly increased the intensity of co-authorship between the periods 1993-2006 and 2007-2017. Even so, all of these changes seem to have had a limited impact on the geography of cooperation. The geographical modules of co-authorship are path-dependent and build upon sets of historical connectivities in trade, knowledge and human exchange. As for the geography of cooperation, shared historical legacies and connectivities remained as important as ever. It is not only geographic distance but also cultural and linguistic borders which impact on the cooperation between scientists. Crossing borders sometimes means entering different cultures and languages. As long as scientific research is conducted by human beings, geographical, cultural and linguistic proximities will remain important determinants of international cooperation in science (Hypothesis 1 ).

The EEG underlines the importance of cognitive, organisational, and social proximity for building networks of knowledge exchange (Boschma, 2005). The regression analysis in this project found a strong and increasing importance of human exchange for explaining co-authorship patterns in the period 2007-2017 compared to 1993-2006 (Hypothesis 2). The importance of human exchange for forming co-authorship ties is at a high level and growing over time. The rise of web-based communication may have greatly sped up the diffusion of codified knowledge, e.g. in terms of papers or patents. Tacit knowledge, however, is no less important for scientific work than before the age of the Web. Human exchange is essential for building relational assets (Essletzbichler and Rigby, 2007). There remains a need for face-to-face communication in order to transmit complex knowledge, be it embedded routines or embodied competences acquired by a person through experience (Bathelt and Henn, 2014). Disseminating tacit knowledge requires informal social interactions and arm's-length market-based relationships.

The network analysis pointed to: (a) a distinctive coreperiphery structure; and (b) considerable stability in the European co-authorship network over a quarter of a century. The centre was identical with a cluster of seven countries (the 'rich club'), while small and/or less developed EEA members formed the periphery. The 2004, 2007 and $2013 \mathrm{EU}$ enlargements was manifested in a subsequent increase in the share of new members in total European publication output. The new members followed trajectories of preferential attachment, as all of them developed connections with influential research partners from the EU15 countries. Over time, some new members formed specific cooperation communities within the periphery, as seen in the formation of such communities following shared historical legacies and cognitive, organisational and social proximity (e.g. the Czech and Slovak communities, or the southern European communities). The emergence of peripheral communities is an example of the mechanism of variation. The three enlargements, however, were not enough to alter processes of cumulative causation in significant ways. Patterns of core and periphery in European co-authorship networks changed little (Hypothesis 3). The dominant position of the 'rich club' remains unchallenged, as the position of the 'rich club' refers to the economic and scientific capacities of its members.

Our research has some important limitations. The findings may be affected by the choice of publication database: even though WOS has better coverage of science than of social science topics. Other limitations relate to the quality of the underlying data. Data on tourist exchange and migration exchange, for example, account for better coverage from 2007-2017 than from 1993-2006. Further research will, undoubtedly, benefit from longer time series and better data coverage.

Further research may consider the following directions. An obvious option is to extend the geographical coverage of the research. Knowledge of diffusion networks between European and neighbouring countries are weaker than those between European countries (Autant-Bernard et al., 2017), but may follow the same types of connectivities in merchandise trade, trade in knowledge, and human exchange. This paper has used co-authorship patterns as proxies for the transfer of tacit knowledge over distance. Alternative proxies (dependent variables) may include the composition of committees and boards in international organisations and multinational companies. Another option is to explore alternative connectivities (independent variables). One area worthy of investigation is that European countries follow diverse legal

\footnotetext{
${ }^{6}$ Multinational co-authorship allows for total shares higher than $100 \%$ by particular countries.
} 
systems. Comparative law studies, for example, recognise French, German and Scandinavian civil laws, as well as a number of hybrid systems. Common legal systems may induce higher trust and understanding, and decrease transaction costs amongst research partners (Felbermayr and Toubal, 2010). Research may test the hypothesis that similarities and/or differences in law systems impact upon the choice of project partners and, indirectly, co-authorship patterns.

In addition, some European countries tend to form specific regional cooperation bodies, such as the Nordic Council or the Visegrád Four Group. Some regional cooperation bodies provide research funding for regional partner scientists and institutions. Country membership in regional bodies usually originates in shared historical legacies, geographical proximities, and linguistic and cultural affinities. Such affinities manifest in many, often unexpected, patterns of cooperation, such as 'voting alliances' in the Eurovision Song Contest (Budzinski and Pannicke, 2017). Do 'friend or foe' alliances (García and Tanase, 2013) manifest only in emotionladen song contests, or are they present in (supposedly rational) choices of research partners as well? There are some very interesting questions in these reflections.

In this paper we have concentrated on the role of general socio-economic spaces in the formation of co-authorship networks. Further research may analyse the role of sciencespecific support tools in forming research partnerships and in creating co-authorship networks. The Framework and Horizon Programmes were the obvious candidates in the past (Breschi and Cusmano, 2004; Barber and Scherngell, 2013). Alternative specific support tools may include supranational research projects developed under the COST, EUREKA and ERA-NET schemes, joint technology platforms, and shared research infrastructures.

\section{Acknowledgment}

This research was supported by Slovak VEGA Grant No. 2/0002/18 and VEGA Grant No. 2/0097/19.

\section{References:}

ABBASI, A., HOSSAIN, L., UDDIN, S., RASMUSSEN, K. J. R. (2011): Evolutionary Dynamics of Scientific Collaboration Networks: Multi-Levels and Cross-time Analysis. Scientometrics, 89(2): 687-710.

AUTANT-BERNARD, C., CHALAYE, S., GAGLIARDINI, E., USAI, S. (2017): European knowledge neighbourhood: Neighbouring countries and intensity of the relationship with the EU countries. Tijdschrift voor Economische en Sociale Geografie, 108(1): 52-75.

BALLAND, P. A., SUIRE, R., VICENTE, J. (2013): Structural and geographical patterns of knowledge networks in emerging technological standards: evidence from the European GNSS industry. Economics of Innovation and New Technology, 22(1): 47-72.

BARBER, M. J., SCHERNGELL, T. (2013): Is the European R\&D network homogeneous? Spatial interaction modelling of network communities determined using graph theoretic methods. Regional Studies, 47(8): 1283-1298.

BARRAT, A., BARTHELEMY, M., PASTOR-SATORRAS, R., VESPIGNANI, A. (2004): The architecture of complex weighted networks. Proceedings of the National Academy of Sciences of the United States of America, 101(11): 3747-3752.
BATHELT, H., GLÜCKLER, J. (2011): The Relational Economy: Geographies of Knowing and Learning, Oxford, Oxford University Press.

BATHELT, H., HENN, S. (2014): The geographies of knowledge transfers over distance: toward a typology. Environment and Planning A, 46(6): 1403-1424.

BERGÉ, L. R., WANZENBÖCK, I., SCHERNGELL, T. (2017): Centrality of regions in R\&D networks: a new measurement approach using the concept of bridging paths. Regional Studies, 51(8): 1165-1178.

BLACKLER, F. (2002): Knowledge, knowledge work, and organizations. An Overview and Interpretation. In: The Strategic Management of Intellectual Capital and Organizational Knowledge, C. W. Choo and N. Bontis, pp. 47-64. Oxford, Oxford University Press.

BOSCHMA R.A. (2005): Proximity and Innovation: A Critical Assessment, Regional Studies 39(1): 61-74.

BOSCHMA, R., FRENKEN, K. (2006): Why is economic geography not an evolutionary science? Towards an evolutionary economic geography. Journal of Economic Geography 6 (3): 273-302.

BRESCHI, S., CUSMANO, L. (2004): Unveiling the Texture of a European Research Area: Emergence of Oligarchic Networks under EU Framework Programmes. International Journal of Technology Management, 27(8): 747-772.

BROWN, T. A. (2014): Confirmatory Factor Analysis for Applied Research. Second Edition, Guilford Publications.

BUDZINSKI, O., PANNICKE J. (2017): Culturally biased voting in the Eurovision Song. Contest: Do national contests differ? Journal of Cultural Economics, 41(4) 343-378.

CHESSA, A., MORESCALCHI, A., PAMMOLLI, F., PENNER, O., PETERSEN, A. M., RICCABONI, M. (2013): European policy. Is Europe evolving toward an integrated research area? Science 339(6120): 650-651.

COLIZZA V., FLAMMINI, A., SERRANO, M. A., VESPIGNANI, A. (2006): Detecting rich-club ordering in complex networks. Nature Physics 2(2): 110-115.

COSTELLO, A. B., OSBORNE, J. W. (2005): Best Practices in Exploratory Factor Analysis: Four Recommendations for Getting the Most from Your Analysis. Practical Assessment Research \& Evaluation, 13(4): 1-9.

DISTEFANO, C., ZHU, M., MÎNDRILĂ, M. (2009): Understanding and Using Factor Scores: Considerations for the Applied Researcher. Practical Assessment, Research \& Evaluation, 14(20): 1-11.

DE WINTER, J., DODOU, D., WIERINGA, P. A. (2009): Exploratory Factor Analysis with Small Sample Sizes. Multivariate Behavioral Research, 44(2): 147-181.

DE PRATO, G., NEPELSKI, D. (2014): Global technological collaboration networks: network analysis of international co-inventions. The Journal of Technology Transfer, 39(3): 358-375.

EASLEY, D., KLEINBERG, J. (2010): Networks, Crowds, and Markets Reasoning About a Highly Connected World. Cambridge: Cambridge University Press.

EC European Commission (1994-2013): Official Journal (OJ) of the European Union; OJ L126 - 18/05/1994, No. 1110/94/EC; OJ L26 - 01/02/1999, No. 182/1999/EC; OJ L232 - 29/08/2002; No. 1513/2002/EC; OJ L391 - 
30/12/2006, No. 2006/969/EC; OJ L412 - 20/12/2006, No. 1982/2006/EC; OJ L347 - 20/12/2013, No. 2013/743/EU; Luxembourg: Publications Office of the European Union.

ESSLETZBICHLER, J., RIGBY, D. L. (2007): Exploring evolutionary economic geographies, Journal of Economic Geography 7(5): 549-571.

EUROSTAT (2019): Statistical database, Statistical office of the European Communities [cit. 31.12.2018]. Available at: https://ec.europa.eu/eurostat/data/database

FELBERMAYR, G. J., TOUBAL, F. (2010): Cultural proximity and trade. European Economic Review, 64(2): 279-293.

FRENKEN, K., HOEKMAN, J., KOK, S., PONDS, R., VANOORT, F., VAN VLIET, J. (2009): Death of distance in science? A gravity approach to research collaboration. In: Pyka, A., Scharnhorst, A. [eds.]: Innovation Networks. (pp. 43-57). New York, Springer-Verlag.

FRENKEN, K., HARDEMAN, S., HOEKMAN, J. (2009): Spatial scientometrics: towards a cumulative research program. Journal of Informetrics, 3(3): 222-232.

FRUCHTERMAN， T. M. J， REINGOLD， E. M. (1991): Graph Drawing by Force-Directed Placement. Software: Practice and Experience, 21(11): 1129-1164.

GARCÍA, D., TANASE, D. (2013): Measuring Cultural Dynamics through the Eurovision Song Contest. Advances in Complex Systems, 16(8): 135007.

GLÜCKLER, J. (2007): Economic geography and the evolution of networks, Journal of Economic Geography Advance, 7(5): 619-634.

HAVEMAN, J., HUMMELS, D. (2004): Alternative Hypotheses and the Volume of Trade: The Gravity Equation and the Extent of Specialization. The Canadian Journal of Economics / Revue canadienne d'Economique, 37(1): 199-218.

HELPMAN, E., MELITZ, M., RUBINSTEIN, Y. (2008): Estimating trade flows: trading partners and trading volumes. Quarterly Journal of Economics, 123(2): 441-487.

HOEKMAN, J., FRENKEN, K., TIJSSEN, R. (2010): Research collaboration at a distance: changing spatial patterns of scientific collaboration in Europe. Research Policy, 39(5): 662-673.

HOLSTE, J. S., FIELDS, D. (2010): Trust and tacit knowledge sharing and use. Journal of Knowledge Management, 14(1): 128-140.

HOWELLS, J.R. L. (2000): Knowledge, innovation and location, In: Bryson, J. R., Daniels, P.W., Henry, N., Pollard, J.: Knowledge, Space, Economy (pp. 50-62). London, Routledge.

HOWELLS, J. R. L. (2002): Tacit Knowledge, Innovation and Economic Geography. Urban Studies, 39(5-6): 871-884.

JENNISSEN, R. (2007): Causality Chains in the International Migration Systems Approach. Population Research and Policy Review, 26(4): 411-436.

LUUKKONEN, T., PERSSON, O., SIVERTSEN, G. (1992): Understanding Patterns of International Scientific Collaboration. Science. Technology \& Human Values, 17(1): 101-126.

GUI, Q., LIU, C., DU, D. (2018): International knowledge flows and the role of proximity. Growth and Change, 49(3): 532-547.
KOEGLER, D. F. (2015): Editorial: Evolutionary Economic Geography - Theoretical and Empirical Progress. Regional Studies 49(5): 705-711.

MASKELL, P., MALMBERG, A. (1999): Localised Learning and Industrial Competitiveness. Cambridge Journal of Economics, 23(2): 167-185.

MCKINNON, D., CUMBERS, A., PIKE A., BIRCH, K., MCMASTER. R. (2009): Evolution in Economic Geography: Institutions, Political Economy, and Adaptation. Economic Geography, 85(2): 129-150.

MIGUÈLEZ, E., MORENO, R. (2013): Do labour mobility and technological collaborations foster geographical knowledge diffusion? The case of European regions. Growth and Change, 44(2): 321-354.

MONTOBBIO, F., STERZI, V. (2013): The Globalization of Technology in Emerging Markets: A Gravity Model on the Determinants of International Patent Collaborations. World Development, 44(C): 281-299.

MORAVCSIK, A. (1991): Negotiating the Single European Act: national interests and conventional statecraft in the European Community. International Organization, 45(1): 19-56.

MORESCALCHI, A., PAMMOLLI, F., PENNER, O., PETERSEN, A. M., RICCABONI, M. (2015): The evolution of networks of innovators within and across borders: Evidence from patent data. Research Policy, 44(3): 651-668.

NEDEVA, M. (2012): From "Science in Europe" to "European Science". Science, 333(6084): 982-983.

NEWMAN, M. E. J. (2004): Coauthorship networks and patterns of scientific collaboration. Proceedings of the National Academy of Sciences of the United States of America. 101 (Suppl. 1): 5200-5205.

NEWMAN, M.E.J. (2006): Modularity and community structure in networks. Proceedings of the National Academy of Sciences of the United States of America 103(23): 8577-8582.

NONAKA, I., VON KROGH, G. (2009): Tacit Knowledge and Knowledge Conversion: Controversy and Advancement in Organizational Knowledge Creation Theory. Organization Science, 20(3): 635-652.

OECD (2019): OECD Statistical database, Organisation for Economic Co-operation and Development website [cit. 31.12.2018]. Available at: https://stats.oecd.org/

OPSAHL, T., COLIZZA, V., PANZARASA, P., RAMASCO, J. J. (2008): Prominence and control: The weighted rich-club effect. Physical Review Letters, 101(18): 168702.

OSBORNE, J. W. (2015): What is Rotating in Exploratory Factor Analysis? Practical Assessment. Research \& Evaluation, 20(18): 1-7.

PACI, R., USAI, S. (2009): Knowledge flows across European regions. The Annals of Regional Science, 43(3): 669-690.

PAN, R. K., KASKI, K., FORTUNATO, S. (2012): World citation and collaboration networks: uncovering the role of geography in science. Scientific Reports, 2(902).

POLANYI, M. (1966): The Tacit Dimension. Garden City, New York, Doubleday and Co.

QUATRARO, F., USAI, S. (2016): Are knowledge flows all alike? Evidence from European regions. Regional Studies, 51(8): 1-13. 
RAMOS, R. (2016): Gravity models: A tool for migration analysis. IZA World of Labor 2016: 239.

TONER, P., WOOLLEY, R. (2008): Temporary Migration and Skills Formation in the Trades: a Provisional Assessment. People and Place 16(3): 47-57.

UNCTAD (2018): Statistical database [online]. [cit. 15.012.2018]. United Nations Conference on Trade and Development website Available at: https:/unctadstat. unctad.org/wds/ReportFolders/reportFolders.aspx?sCS ChosenLang $=$ en

WAGNER, C., PARK, H., LEYDESDORFF, L. (2015): The continuing growth of global cooperation networks in research: a conundrum for national governments. PLOS One,10(7): e0131816
WAGNER, C. S., WHETSELL, T. A., LEYDESDORFF, L. (2017): Growth of international collaboration in science: revisiting six specialties. Scientometrics, 110(3): 1633-1652.

WEI, Y., SONG, S., XIU, C., ZHAO, Z. (2018): The richclub phenomenon of China's population flow network during the country's spring festival. Applied Geography, 96(July): 77-85.

ZLATIC, V., BIANCONI, G., DÍAZ-GUILERA, A., GARLASCHELLI, D., RAO, F. CALDARELLI, G. (2009): On the rich-club effect in dense and weighted networks. The European Physical Journal B, 67(3): 271-275.

\section{Please cite this article as:}

JECK, T., BALÁŽ, V. (2020): Geographies of tacit knowledge transfer: Evidence from the European co-authorship network. Moravian Geographical Reports, 28(2): 98-111. Doi: https://doi.org/10.2478/mgr-2020-0008

\begin{tabular}{|c|c|c|c|c|c|c|c|c|c|c|}
\hline & \multicolumn{5}{|c|}{ 1993-2006 } & \multicolumn{5}{|c|}{ 2007-2017 } \\
\hline & $\mathrm{N}$ & Min & Max & Mean & Std. Dev & $\mathrm{N}$ & Min & Max & Mean & Std. Dev \\
\hline $\mathrm{CA}$ & 868 & 0.01 & 38.35 & 3.46 & 4.60 & 870 & 0.04 & 25.05 & 3.45 & 3.66 \\
\hline PFCI & 604 & 0.01 & 62.33 & 4.97 & 8.21 & 664 & 0.01 & 53.85 & 4.52 & 7.40 \\
\hline FODI & 557 & 0.01 & 57.14 & 5.39 & 8.17 & 620 & 0.01 & 46.37 & 4.84 & 6.96 \\
\hline DOIMA & 557 & 0.01 & 62.08 & 5.39 & 8.84 & 620 & 0.01 & 57.23 & 4.84 & 8.38 \\
\hline ME & 870 & 0.00 & 55.60 & 3.45 & 6.47 & 870 & 0.00 & 50.96 & 3.45 & 6.17 \\
\hline MI & 870 & 0.01 & 42.62 & 3.45 & 6.04 & 870 & 0.01 & 40.05 & 3.45 & 5.68 \\
\hline SMCOE & 697 & 0.00 & 89.31 & 4.30 & 10.61 & 792 & 0.00 & 85.22 & 3.79 & 9.47 \\
\hline ISCOE & 614 & 0.00 & 90.74 & 4.72 & 10.43 & 718 & 0.00 & 90.25 & 4.18 & 9.43 \\
\hline NSET & 498 & 0.02 & 79.03 & 5.62 & 9.85 & 727 & 0.00 & 68.04 & 4.13 & 8.19 \\
\hline
\end{tabular}

Appendix 1: Descriptive statistics

Notes: CA = co-authorships (Source: Web of Science Core Collection database (2019), time series available since 1993); PFCI = Patents with foreign co-inventor(s); FODI = Foreign ownership of domestic inventions; DOFI = Domestic ownership of foreign inventions (Source: OECD.Stat, 2019: International co-operation in patents; all time series available since 1993); $M E$ = Shares of each European trading partner in total European merchandise exports by country of origin; $M I=$ Shares of each European trading partner in total European merchandise imports by country of origin (Source: UNCTAD, 2019: International trade in goods and services; Merchandise: Total trade and share, annual; time series available since 1995); SMCOE = Share of European migrants from a country of origin in all European destinations (Source: Eurostat, 2019: Population on $1^{\text {st }}$ January by age group, sex and citizenship-Country of citizenship; time series available since 1998); ISCOE = Share of international students from a country of origin in all European student destinations (Source: OECD.Stat, 2019: Foreign / international students enrolled (to 2012), and enrolment of international students by origin (from 2013); time series available since 1998); NSET = Share of nights spent by European partner tourists in partner countries (Source: Eurostat, 2019: Number of nights spent by country / world region of destination; time series available since 1994) 


\begin{tabular}{|c|c|c|c|c|c|c|c|c|c|}
\hline 1993-2006 & CA & PFCI & FODI & DOIMA & ME & MI & SMCOE & ISCOE & NSET \\
\hline $\mathrm{CA}$ & 1 & $0.823^{* *}$ & $0.761^{* *}$ & $0.720^{* *}$ & $0.829 * *$ & $0.828^{* *}$ & $0.741^{* *}$ & $0.836^{* *}$ & $0.743^{* *}$ \\
\hline PFCI & $0.823^{* *}$ & 1 & $0.791^{* *}$ & $0.894^{* *}$ & $0.804^{* *}$ & $0.810^{* *}$ & $0.744^{* *}$ & $0.770^{* * *}$ & $0.709^{* * *}$ \\
\hline FODI & $0.761^{* *}$ & $0.791 * *$ & 1 & $0.671^{* *}$ & 0.760 ** & $0.760 * *$ & $0.635^{* *}$ & $0.675^{* *}$ & $0.646^{* * *}$ \\
\hline DOIMA & $0.720^{* *}$ & $0.894^{* *}$ & $0.671^{* *}$ & 1 & $0.694^{* *}$ & $0.706^{* *}$ & $0.702^{* *}$ & $0.677^{\text {** }}$ & $0.702^{* * *}$ \\
\hline $\mathrm{ME}$ & $0.829^{* *}$ & $0.804^{* *}$ & $0.760^{* *}$ & $0.694^{* *}$ & 1 & $0.907^{* *}$ & $0.744^{* *}$ & $0.757^{* *}$ & $0.696^{* * *}$ \\
\hline MI & $0.828^{* *}$ & $0.810^{* *}$ & $0.760^{* * *}$ & $0.706^{* *}$ & $0.907^{* *}$ & 1 & $0.730 * *$ & $0.727^{* * *}$ & $0.713^{* * *}$ \\
\hline SMCOE & $0.741^{* *}$ & $0.744^{* *}$ & $0.635^{* *}$ & $0.702^{* *}$ & $0.744^{* *}$ & $0.730 * *$ & 1 & $0.815^{\text {** }}$ & $0.756^{* *}$ \\
\hline ISCOE & $0.836^{* *}$ & $0.770 * *$ & $0.675^{* *}$ & $0.677^{* * *}$ & $0.757^{* *}$ & $0.727^{* *}$ & $0.815^{* *}$ & 1 & 0.750 ** \\
\hline NSET & $0.743^{* *}$ & 0.709 ** & $0.646^{* *}$ & $0.702^{* *}$ & $0.696^{* *}$ & $0.713^{* *}$ & $0.756^{* *}$ & $0.750^{* * *}$ & 1 \\
\hline 2007-2017 & CA & PFCI & FODI & DOIMA & ME & MI & SMCOE & ISCOE & NSET \\
\hline $\mathrm{CA}$ & 1 & $0.773 * *$ & $0.763^{* *}$ & $0.577^{* *}$ & $0.766^{* *}$ & $0.788^{* *}$ & $0.691 * *$ & $0.749^{* *}$ & 0.709 ** \\
\hline PFCI & $0.773^{* *}$ & 1 & $0.820^{* *}$ & $0.860^{* *}$ & $0.787^{* *}$ & $0.808^{* *}$ & 0.679 ** & $0.670^{* * *}$ & $0.739 * *$ \\
\hline FODI & $0.763^{* *}$ & $0.820^{* *}$ & 1 & $0.604^{* *}$ & $0.717^{* *}$ & $0.740^{* *}$ & $0.579 * *$ & $0.611^{* *}$ & $0.630^{* *}$ \\
\hline DOIMA & $0.577^{* * *}$ & $0.860 * *$ & $0.604^{* *}$ & 1 & $0.621^{* *}$ & $0.619 * *$ & $0.527^{* *}$ & $0.457^{\text {*** }}$ & $0.637^{* * *}$ \\
\hline $\mathrm{ME}$ & $0.766^{* *}$ & $0.787 * *$ & $0.717^{* *}$ & $0.621^{* *}$ & 1 & $0.910^{* *}$ & 0.650 ** & 0.619 ** & $0.721^{* *}$ \\
\hline MI & $0.788^{* *}$ & $0.808^{* *}$ & $0.740 * *$ & $0.619^{* *}$ & 0.910 ** & 1 & $0.648^{* *}$ & $0.608^{* *}$ & $0.716^{* * *}$ \\
\hline SMCOE & $0.691^{* *}$ & 0.679 ** & $0.579 * *$ & $0.527^{* *}$ & 0.650 ** & $0.648^{* *}$ & 1 & $0.807^{\text {*** }}$ & $0.765^{* * *}$ \\
\hline ISCOE & $0.749 * *$ & $0.670^{* *}$ & $0.611^{* *}$ & $0.457^{* * *}$ & 0.619 ** & $0.608^{* *}$ & $0.807 * *$ & 1 & $0.727^{* *}$ \\
\hline NSET & $0.709^{* *}$ & $0.739^{* *}$ & $0.630^{* *}$ & $0.637^{* *}$ & $0.721^{* *}$ & $0.716^{* *}$ & $0.765^{* *}$ & $0.727^{* * *}$ & 1 \\
\hline
\end{tabular}

Appendix 2: Correlation matrices for dependent and independent variables Notes: ** Correlation is significant at the 0.01 level (2-tailed) 